the community. Strengthening the human rights approach, organisations for young psychiatrists, international collaboration and additional attention to the region are among the possible solutions.

\section{References}

Dlouhy, M. (2014) Mental health policy in Eastern Europe: a comparative analysis of seven mental health systems. BMC Health Services Research, 14, 42

Forsman, A. K., Ventus, D. B. J., van der Feltz-Cornelis, C. M., et al (2014) Public mental health research in Europe: a systematic mapping for the ROAMER project. European Journal of Public Health, 24, 955-960.

Füredi, J., Mohr, P., Swingler, D., et al (2006) Psychiatry in selected countries of Central and Eastern Europe: an overview of the current situation. Acta Psychiatrica Scandinavica, 114, 223-231.

Lozano, R., Naghavi, M., Foreman, K., et al (2012) Global and regional mortality from 235 causes of death for 20 age groups in 1990 and 2010: a systematic analysis for the Global Burden of Disease Study 2010. Lancet, 380, 2095-2128.

Saraceno, B., van Ommeren, M., Batniji, R., et al (2007) Barriers to improvement of mental health services in low-income and middleincome countries. Lancet, 370, 1164-1174.
Semrau, M., Barley, E. A., Law, A., et al (2011) Lessons learned in developing community mental health care in Europe. World Psychiatry, 10, 217-225.

Taylor Salisbury, T., Killaspy, H. \& King, M. (2016) An international comparison of the deinstitutionalisation of mental health care: development and findings of the Mental Health Services Deinstitutionalisation Measure (MENDit). BMC Psychiatry, 16, 54. Available at http://www.pubmedcentral.nih.gov/articlerender.fcgi?artid=4772656 \&tool=pmcentrez\&rendertype=abstract (accessed 30 May 2016).

van Voren, R., Tomov, T., Keukens, R., et al (2007) Mental health policy and practice across Europe. In Mental Health Policy and Practice Across Europe (eds M. Knapp, et al), pp. 397-425. Open University Press.

WHO (2011) Mental Health Atlas - 2011 country profiles. Available at http://www.who.int/mental_health/evidence/atlas/profiles/en/ (accessed 11 February 2016).

WHO (2012) Suicide data. Available at http://www.who.int/mental health/prevention/suicide/suicideprevent/en/WHO (accessed 4 April 2015).

WHO (2014a) Global Status Report on Alcohol and Health 2014 Available at http://www.who.int/substance abuse/publications/ global_alcohol_report/en (accessed 4 April 2015).

WHO (2014b) Mental Health Atlas - 2014 country profiles. Available at http://www.who.int/mental_health/evidence/atlas/ profiles-2014/en (accessed 11 February 2016)

\title{
Hysterical stupor or yogic sleep?
} The conundrum

\author{
Manohar Dhadphale
}

Academic Head, Kamala Nehru Hospital, Pune, India, email manohar_dhadphale@yahoo. co.uk

\begin{abstract}
A woman in the care of the author 40 years ago was reported to have been sleeping for 2 days. We treated her condition as conversion hysteria. Her private psychiatrist was the renowned R. D. Laing; he was unhappy with our line of management, on the grounds of the arbitrariness of the diagnosis, the labelling of the woman with a diagnosis of hysteria and the treatment of the patient without her consent. In retrospect, I wonder if she was in a state of yogic sleep (yoga nidra).
\end{abstract}

After practising for more than a dozen years (1958-70) in rural and remote parts of Kenya, then known as the Colony and Protectorate, I came to England to train as a psychiatrist. My first clinical posting was in a rapidly changing Victorian mental hospital in south-west London (which closed down decades ago). In my practice at home in rural Kenya, the diagnosis of hysteria was made mainly by excluding a physical basis for the patient's symptoms. I had seen and treated many patients with fits, bizarre and vague symptoms such as abdominal pain, heat in the forehead and dudus (insects) crawling all over the back or legs at certain times of the day. As a general practitioner in the African countryside in the 1960s and 1970s, the treatment was purely symptomatic and supportive.
I came to the UK to train as a psychiatrist and return to Africa after training. Here, I describe an interesting and memorable experience. As a thirdyear trainee, I came face to face with a leading anti-psychiatrist. I had seen one of the latter's patients, who I thought was in a hysterical stupor. The anti-psychiatrist was unhappy with my assessment, diagnosis and management.

\section{Case details}

Mrs G was a 64-year-old woman referred to my consultant. I admitted her to his unit in the hospital. He had telephoned and informed me that this was a well connected woman, very active socially but who lived on her own, as her husband, a highranking officer, was posted in Africa. For the last 2 days she had been sleeping (she had not got up nor had she eaten). She had been visiting a private psychiatrist in London for reasons unknown to the husband. She was not on any medication. The couple had no children. They lived in a mansion in the countryside. They enjoyed travelling abroad. Mrs G had a live-in domestic. She drank socially, did not smoke and enjoyed reading books on psychology, mental health, yoga and meditation. She enjoyed excellent health.

After admission, we telephoned her husband to ask about social and mental health issues. He told us that their marriage was happy, his wife 
was a cheerful person, always busy helping people in distress. She was a leading member of social groups and a mental health activist. He knew that she was seeing a private psychiatrist but could not say why. He did not think there was any significant life event to cause the present 'breakdown'. She had gone to Africa the previous month and they had travelled together in the countryside for a week. She was happy on her return to the UK.

On admission, Mrs G was sleeping and did not respond to any questions. She could not be roused. The clinical and neurological examinations were normal. The pupils were equal and reacted to light. She was unresponsive to light pinching. Her pulse rate, blood pressure, heart rate and other vital functions were normal. She was not dehydrated and looked healthy.

She was kept under close observation. I sent relevant samples to the laboratory, arranged for a skull radiograph and lumbar puncture and requested expert opinions from the physician and neurologist. Her blood and cerebrospinal fluid tests for malarial parasites were negative.

The following day the neurologist and the physician saw her. After clinical examination and scrutiny of the test results, the neurologist did not think there was any neurological illness and believed we were dealing with a conversion disorder. He thought the patient was asleep. Similarly, the physician did not find anything physically wrong with her and advised us to look after her nutrition, hydration and personal hygiene. He concurred with the neurologist's opinion.

We kept her under observation and monitored her progress. No change had been noticed in her physical or mental condition in the 48 hours since admission. Therefore, the following morning (day 3) the team discussed giving her electroconvulsive therapy (ECT) if there was no change in her condition in the next 24 hours. We were now getting concerned and requested an assessment by an approved social worker (ASW) under the Mental Health Act. The team discussed the clinical situation and concluded that she was in a stupor. Any serious neurological or physical illness was considered unlikely. Catatonia was excluded on clinical grounds. Our differential diagnosis was thus narrowed down to depressive or hysterical stupor. At the end of day 3, we believed that if it were the former then ECT would be beneficial; and for the latter, we would consider other forms of therapy. Her private psychiatrist was still away. We concluded that ECT would be justifiable in the circumstances.

When I saw her the following morning there had been no change in her mental condition. Therefore, we informed the ASW that ECT was provisionally booked for that afternoon and we would appreciate his assessment. Two hours later I was urgently called to the ward. I was amazed to find Mrs G fully conscious. She sat in a chair sipping a cup of tea and was requesting the nurse to run the bath, call the hairdresser, get her fresh clothes and book a cab to take her to her psychiatric appointment. She was furious when she saw me and accused me of detaining her and giving her humiliating treatment. I was a registrar at that time and did not know how to handle the situation. I called my senior, who advised me to remain calm and let her see her psychiatrist. He suggested I call her consultant and report our concerns. In the meantime, I should cancel the ECT and inform the ASW.

She had lunch, a bath and attention from the hairdresser. She was ready for her psychiatric appointment but turned down our escort and left. She returned 4 hours later and informed us that she was going home. When asked about the visit, she was testy, and told me that her doctor was livid with our mismanagement and would soon be talking to me. My consultant advised me to let her go home.

Her psychiatrist called me the following day. My anxiety rose when I realised that it was Dr R. D. Laing, a leading luminary of the anti-psychiatry movement. He was at the pinnacle of his reputation in the early 1960s and 1970s (Burston, 1996). During my training, I had been intrigued by the anti-psychiatrist movement. I had read Szasz's The Myth of Mental Illness (1961) and Laing's The Divided Self (1960).

Laing spoke calmly in his educated Glasgow accent. Before I could tell him about Mrs G's admission, he started a barrage of questions that unnerved me. He dismissed my argument that we were dealing with conversion disorder. He refused to accept my argument for the diagnosis because I could not establish the existence of a traumatic situation in Mrs G's life situation before her admission (primary gain). He firmly told me that we were not dealing with a mental illness and he dismissed my arguments in support of my diagnosis. He pointed out that dozens of criteria for diagnosis in the ICD and DSM systems were vague and arbitrary; therefore, there was wide scope for opinions and serious misinterpretations. He also referred to the abuse of power by confused psychiatrists. He terminated the discussion by concluding that the patient had no mental illness and derided us for mismanagement. The following morning I received through the post two books, Laing's Sanity, Madness and the Family (1964) and The Divided Self (1960).

Two days later, I called to thank him for his gift of books. He was calm and happy, and informed me that Mrs $\mathrm{G}$ was doing well. He reiterated that she did not have a mental illness but had learned to go to sleep at will. He recommended that I read about the sleep techniques based on yoga and meditation. He berated those who do not understand the patient's life situation and label them hysterical. After he had finished I wondered whether I was more enlightened or perplexed about hysteria!

\section{Comments}

Mrs G's case was an excellent learning experience during my training. It had a bearing on my later career as a psychiatrist and a teacher. Two issues merit further elucidation: the diagnosis of 
conversion (dissociation), which Laing vehemently discarded; and the concept of the then almost unknown condition, yogic sleep (yoga nidra).

The diagnostic term 'hysteria' or 'conversion disorder' had been used well before Breuer and Freud wrote Studies on Hysteria (1885). We believed the diagnosis in this case was conversion disorder, based on clinical evaluation, observations, satisfying the ICD criteria and exclusion of an organic condition. Her psychiatrist argued that we had not established the primary gain, a cardinal feature in the diagnosis of conversion. I concede this point. In practice, it is not always easy to find a psychosocial stressor in every case of conversion disorder.

The very concept of conversion has recently been challenged. It has come under severe scrutiny during the revision of ICD-11 and DSM-5, and Reynolds (2012) has highlighted this dilemma in an editorial in the BJPsych. Suggestions are advanced to replace the term 'conversion disorder' with 'functional neurological disorder'. Commenting on the diagnosis of conversion disorder in new editions of ICD and DSM, Dimsdale \& Creed (2009) and Stone et al (2010) and others have suggested abandoning the term. The points against the diagnosis of conversion are, among others: (1) 'conversion' is based on a questionable psychoanalytic concept; (2) it is not widely used by non-psychiatrists and is not liked by patients; and (3) current diagnostic criteria require a psychosocial association with symptom onset that is difficult to find in some patients, and when present is of questionable value.

However, 'functional neurological disorder' is also a questionable diagnostic term for neurologists. They find it difficult to accept because a neurological cause cannot be established in (functional) conversion disorders (Kanaan et al, 2012). I would concur with Reynolds (2012) that the discussion of this contentious issue should start with the argument that, in conversion disorder, the symptoms are neurological but of psychological origin.

In 1973, I was unaware of yoga nidra (yogic sleep). It is a concept in ancient Hindu and Buddhist philosophy. It is described as a state of conscious sleep, with deep awareness and inward lucidity. It involves aimless and effortless relaxation (Annandmurti Gurumaa; see htpp://www.gurumaa.com). Did Mrs G know of the principles and practice of yogic sleep or yoga nidra? This explanation of Mrs G's situation must remain speculative. Laing had spent several months in Sri Lanka and India studying yoga and meditation in a Buddhist resort and an Indian ashram (Thomson, 1996). Perhaps he was familiar with the concept of yoga nidra. I wonder if we could use yoga nidra today to treat some sleep disorders.

Yogic sleep recently featured in the Indian press (Indian Express, 14 October 2015). Under the headline 'Musical problems' a story was reported that involved Lord Padnabhswamy (reincarnation of the Hindu God Lord Vishnu). In the most famous and holy temple in Thiruvanthpuram
(Kerala, India), the Lord's idol appears in the pose of yoga nidra (a position of perfect relaxation and sleep). He is awakened by a particular melody called suprabhatam ('good morning'). A dispute arose among the devotees: some wanted to change the wake-up call, while others did not. The matter was referred to the Supreme Court of India. The learned judges admitted their lack of expertise on yoga nidra.

After I finished my training in the UK, I returned to Africa. Before diagnosing hysteria, I endeavoured to identify a psychological precipitant, if any. However, in busy and crowded clinics it was not always possible to do so. Every time I made the diagnosis of hysteria, I remember what the anti-psychiatrist had cautioned me about. Personally, I believe the diagnosis of hysteria is acceptable but must be based on evidence and not merely by exclusion of an organic condition. I often wonder if Mrs G were to be admitted in similar circumstances today, 43 years later, would the diagnosis or management be any different? From my experience in the UK, Kenya, Zambia, and now India, I would say no.

At a crucial time in my career, my interaction, though brief, with Dr R. D. Laing had an enduring effect on my understanding of the elusive term 'hysteria'. This was perceptible in my nationwide prevalence study in rural Kenya (Dhadphale, 1983). I interviewed more than 200 psychiatric patients in a two-stage screening process; only $2 \%$ of them were confirmed as having hysteria, mostly because I could demonstrate the "primary gain'. I concur with Dr Laing's views regarding the arbitrariness of psychiatric diagnosis, as well as on the point of covert influence of the pharmaceutical industry on our prescription practices.

\section{References}

Breuer, J. \& Freud, S. (1885) Studies on Hysteria (trans. and ed .J Strachey). Basic Books.

Burston, D. (1996) The Life and Work of Dr R. D. Laing. Harvard University Press.

Dhadphale, M. (1983) Prevalence of psychiatric disorders in primary health clinics in rural Kenya. MD thesis, University of Nairobi.

Dimsdale, J. \& Creed, F. (2009) Proposed diagnosis of somatic symptoms disorders in DSM-V to replace somatoform disorders in DSM-IV - a preliminary report. Journal of Psychosomatic Research, $66,473$.

Kanaan, R. A., Carson, A., Wessely, S. C., et al (2012) The function of 'functional': mixed methods of investigation. Journal of Neurology, Neurosurgery and Psychiatry, 83, 248-250.

Laing, R. D. (1960) The Divided Self. Pantheon.

Laing, R. D. \& Easterson, A. (1964) Sanity, Madness and the Family. Basic Books.

Reynolds, E.H. (2012) Hysteria, conversion and functional disorders: neurological contribution to classification issues. British Journal of Psychiatry, 201, 253-254.

Stone, J., Laffrance, W. C., Levenson, J. L., et al (2010) Issues for DSM-5: conversion disorder. American Journal of Psychiatry, 167 626-627.

Szasz, T. (1961) Myth of Mental Illness. Harper and Row.

Thomson, M. G. (1996) Deception, mystification, trauma: Laing and Freud. Psychoanalytic Review, 83, 827-847. 